\title{
Psychometric evaluation of the Hospital Anxiety and Depression Scale in Mexican adults with ischemic and hypertensive cardiomyopathy
}

\author{
Evaluación psicométrica de la Escala de Ansiedad y Depresión Hospitalaria en adultos \\ Mexicanos con cardiopatía isquémica e hipertensiva
}

\author{
Aldo Suárez-Mendoza1, Fernando Petersen-Aranguren², Alejandra Almeida-Velasco ${ }^{1}$, \\ Rebeca Robles-García ${ }^{3}$, Álvaro Camacho ${ }^{4+}$ y Ana Fresán-Orellana ${ }^{5 *}$ \\ ${ }^{1}$ Department of Psychiatry, Neuroscience Institute for Research and Emotional Development, Mexico City; ${ }^{2}$ Department of Medical Clinics, University \\ Center of Health Sciences, University of Guadalajara, Jalisco; ${ }^{3}$ Research Center on Global Mental Health, "Ramón de la Fuente Muñiz" National \\ Institute of Psychiatry, Mexico City. Mexico; ${ }^{4}$ Department of Psychiatry, University of California, San Diego, USA; ${ }^{5}$ Laboratory of Clinical Epidemiology, \\ Directorate of Clinical Research, "Ramón de la Fuente Muñiz" National Institute of Psychiatry, Mexico City. Mexico.
}

\begin{abstract}
Background: Depression and anxiety are frequent comorbid conditions in cardiovascular diseases (CVDs); they are related to poor prognosis and higher mortality risk. Health providers need a clinical tool to identify these psychiatric conditions. The 14-item hospital anxiety and depression scale (HADS) is a screening tool used in patients with different medical conditions. Objective: The aim of this study was to evaluate the psychometric properties of the HADS Mexican Spanish version in a broad sample of Mexican patients with CVDs. Materials and Methods: A total of 953 individuals between 18 and 75 years old with ischemic or hypertensive cardiomyopathy were screened with the HADS Mexican Spanish version. Construct validity, internal consistency, and congruence coefficients of the scale were obtained. Results: The results showed two clear factors which correspond to the original two designated domains of the HADS, anxiety, and depression, with adequate reliability values (alpha $>0.80$ ) and high congruence coefficients $(>0.90)$ when compared to the sample of other validation studies of the HADS. Conclusions: The present study adds evidence of the validity and reliability of the HADS to assess the presence of both depression and anxiety in Mexican patients with CVD. Its central contribution is that it demonstrates its capacity to differentiate the presence and severity of depression and anxiety in this population.
\end{abstract}

Key words: Depression. Anxiety. Cardiovascular disease. Validity. Reliability. Mexico.

\section{Resumen}

Antecedentes: La depresión y la ansiedad son afecciones comórbidas frecuentes en las enfermedades cardiovasculares; se relacionan con mal pronóstico y mayor riesgo de mortalidad. Los proveedores de salud requieren de una herramienta clínica para identificar estas condiciones psiquiátricas. La Escala de Ansiedad y Depresión Hospitalaria de 14 ítems (HADS) es una herramienta de detección utilizada en pacientes con diferentes afecciones médicas. Objetivo: Evaluar las propiedades terms of the CC BYNC-ND license (http://creativecommons.org/licenses/by-nc-nd/4.0/). 
psicométricas de la versión mexicana-española de la HADS en una amplia muestra de pacientes mexicanos con enfermedades cardiovasculares (ECV). Método: Un total de 953 individuos entre 18 y 75 años de edad con cardiomiopatía isquémica o hipertensiva se examinaron con la versión Mexicana en español de la HADS. Se obtuvieron la validez de constructo, la consistencia interna y los coeficientes de congruencia de la escala. Resultados: Los resultados mostraron dos factores que corresponden a los dos dominios designados originales de la HADS, ansiedad y depresión, con valores de confiabilidad adecuados (alfa $>0.80$ ) y altos coeficientes de congruencia ( $>0.90$ ) en comparación con la muestra de otros estudios de validación de la HADS. Conclusiones: El presente estudio sustenta la validez y confiabilidad de la HADS para evaluar la presencia de depresión y ansiedad en pacientes Mexicanos con ECV. Su contribución central es su capacidad para diferenciar la presencia y la gravedad de la depresión y la ansiedad en esta población.

Palabras clave: Depresión. Ansiedad. Enfermedad cardiovascular. Validez. Confiabilidad. México.

\section{Introduction}

By the year 2020, cardiovascular diseases (CVDs), depression, and anxiety are projected to become the leading causes of disability and loss of productivity ${ }^{1}$. They are among the most prevalent diseases worldwide and frequently coexist ${ }^{2}$. In addition, anxiety and depression often take place simultaneously; patients with depression have $47-56 \%$ more probabilities of developing anxiety in their life, while $56 \%$ of the patients suffering from anxiety will develop depression ${ }^{3}$.

Furthermore, depression and anxiety have been recognized by several studies as risk factors for the development of $\mathrm{CVD}^{4-7}$. For decades, mortality associated with depression has reached over $40 \%$ in patients with $C V D^{8,9}$. In fact, the presence of depressive and anxious symptomatology among individuals with CVD has been associated with poor prognosis and a higher risk of mortality independently of disease severity, depression level, or lifestyle $\mathrm{e}^{1,10-12}$. However and despite the negative impact of the co-occurrence of depression and anxiety in CVD patients, diagnosing depression occurs in $<15 \%$ of the cases as pointed out by a study carried out in Poland ${ }^{3}$. Furthermore, a study conducted with 74 patients with acute myocardial infraction found that $69 \%$ and $50 \%$ of the patients had anxiety symptoms and anxiety disorder, respectively; however, they were missed by the health provider ${ }^{13}$.

Due to the high prevalence of these diseases and the overlapping between them, it is extremely important that health providers can recognize such conditions to improve the patient's prognosis by giving them the correct treatment. The hospital anxiety and depression scale (HADS), a self-report instrument which does not require special training for the application and interpretation, is widely used to screen anxiety and depression in patients with different medical conditions because it avoids the overlapping of physical symptoms shared by such emotional and health problems. The scale is integrated by two subscales, each one with 7 items; one for the evaluation of anxiety HADS-A and other for depression HADS-D,14. Multiple studies have demonstrated the good psychometric properties of the scale in different settings and with different population ${ }^{2}$. A review conducted to assess the validity of the HADS concluded that the scale is useful for the detection and severity evaluation of anxiety and depression in a variety of populations ${ }^{15}$. Studies which evaluated the psychometric properties of the scale in patients with CVD also endorse its reliability ${ }^{13,16}$.

In Mexico, there have been several studies assessing the psychometric properties of the HADS Spanish version in different samples, including patients with mental disorders (i.e., eating disorders) ${ }^{17}$, physical illnesses (such as cancer and HIV) $)^{18,19}$, and health issues such as obesity ${ }^{20}$, as well as in cancer caregivers ${ }^{21}$. All of them have proven that HADS is characterized by good psychometric properties for the identification of depression and anxiety in Mexican population.

Recently, Herrera, Galindo, and Lerma in $2018^{22}$ evaluated the HADS in Mexican patients with CVDs, finding a one factorial structure that differs from the original version of the scale with two factors; one for depression and the other for anxiety ${ }^{14}$. The aim of this study is to evaluate the psychometric properties of the HADS Mexican Spanish version in a bigger and without cognitive deficit or psychiatric disorder sample of patients with CVD, specifically in individuals with ischemic or hypertensive cardiomyopathy.

\section{Materials and methods}

\section{Study population}

Recruitment was performed by a convenience sampling approach from adult outpatient services of 12 different hospitals of the second and third level of attention in cardiology throughout the Mexican Republic from March 9, 2016, to January 1, 2017. 
Participants were approached in the waiting area and interviewed by trained staff in the participating hospitals if they met the following inclusion criteria: (1) 18-75 years old, (2) having an ischemic or hypertensive cardiomyopathy diagnosed by a cardiologist, and (3) able to read and write in Spanish. From the 1954 patients approached to the hospitals, only 953 met the inclusion criteria. Participants were excluded from the study if they had cognitive deficit, decline, or any major psychiatric conditions such as psychotic or bipolar disorders. Patients who agreed to participate were given the HADS scale, while they were in the waiting room. Information on cardiovascular risk factors was extracted from the patient's medical record where available. Each participant signed an informed consent to enter into the study. The research project was approved by each hospital's ethics committee and Internal Review Board.

\section{Study instruments}

A detailed sociodemographic questionnaire was generated to collect information on age, gender, level of education, marital status, and employment. Clinical features related to the cardiomyopathy such as illness evolution, history of heart attack, previous surgery, current medications, and comorbid medical conditions were registered. The patient's CVD was documented, assigning them to follow hypertensive heart disease or ischemic heart disease.

The Spanish version of the HADS was used to measure symptoms of depression and anxiety. This scale has 14 items with two subscales; one for depression (pair numbers) and another for anxiety (odd numbers). Each question is scored on a Likert scale from 0 to 3 , whereby 0 is the lowest and 3 the highest severity level of anxiety and depressive symptoms. The final score is obtained by adding up the values of each subscale. Results can range from 0 to 21 . A cutoff point of 11 was used to define a positive screening ${ }^{14}$.

\section{Statistical analysis}

The procedures for testing the psychometric properties of the HADS scale were done as follows: (1) the item discrimination index ${ }^{23}$ with the method of extreme groups $^{24}$ was obtained for each item of the HADS; items with moderate indexes $(<0.30)^{23}$ were eliminated; (2) item correlation was tested and those with a correlation coefficient lower than 0.20 were eliminated; (3) construct validity was determined with an exploratory factor analysis with varimax rotation; items with communalities greater than 0.40 were retained and allocated to factors; and (4) the factor congruence coefficient ${ }^{25,26}$ of the HADS factors were determined using the results of the HADS obtained in a Mexican sample of cancer patients ${ }^{18}$, where a same bifactorial structure was found. Coefficient values $>0.60$ were considered as congruent. All analyses were the SPSS-X version 20 for Windows, PC.

\section{Results}

\section{Sample description}

A total of 953 individuals with ischemic $(n=562,59 \%)$ or hypertensive $(n=391,41 \%)$ cardiomyopathy were included. The mean age was 58.3 years old $(S D=11.1$, range 18-75), with more than half of the participants being men ( $n=573,60.1 \%)$, where $26.9 \%(n=257)$ had secondary school, followed by $24.4 \%$ ( $n=233$ ) with elementary school, 23.8\% ( $n=226)$ had a bachelor's degree, $21.8 \%(n=207)$ completed high school, and the remaining $3.1 \%(n=30)$ had postgraduate studies. At the time of the study, $74.2 \%$ have a couple (married 663 , $69.6 \%$; and cohabiting couple $44,4.6 \%$ ) and $51.9 \%$ $(n=495)$ had a remunerated employment.

Mean evolution of the cardiomyopathy was 6.5 years $(S D=7.2$, range $1-49$ years) and more than $50 \%$ had at least a surgery related to their heart condition $(52.9 \%$, $\mathrm{n}=504$ ). Hypertension and diabetes were the most frequent comorbid conditions, and patients were under several medications when the interview was performed (Table 1).

\section{Item discrimination indices and item correlation coefficients}

The item discriminant indices for the 14 items of the HADS range from good to excellent with values between 0.370 and 0.857 . Furthermore, the item-total correlation coefficients of the items were adequate, ranging from 0.477 to 0.648 . Therefore, all the items of the HADS were included in the subsequent factor analysis.

\section{Factor analysis and internal consistency of the HADS}

The results of the varimax rotation of the 14 items of the HADS accounted for $50.5 \%$ of the variance. The scree plot showed two clear factors that correspond to the original two designated domains of the HADS, named anxiety and depression (Fig. 1). 
Table 1. Clinical characteristics of the sample Cardiomyopathy features ( $\mathrm{n}, \%$ )

\begin{tabular}{|l|c|}
\hline Illness evolution (years) & $6.5 ; 7.2 ; 1-49$ \\
\hline History of heart attack - Yes & $331(34.7)$ \\
\hline History of surgery - Yes & $504(52.9)$ \\
\hline Years elapsed since the last surgery* & $3.3 ; 4.2 ; 1-36$ \\
\hline Main medical comorbidities (n, \%) & \\
\hline Hypertension - yes & $719(75.4)$ \\
\hline Diabetes - yes & $369(38.7)$ \\
\hline Renal failure - Yes & $28(2.9)$ \\
\hline Dyslipidemia - yes & $262(27.5)$ \\
\hline Respiratory diseases - yes & $38(4.0)$ \\
\hline Chronic obstructive pulmonary disease - yes & $21(2.2)$ \\
\hline Asthma - yes & $16(1.7)$ \\
\hline Both - yes & $1(0.1)$ \\
\hline Current treatment (n, \%) & \\
\hline Acetylsalicylic acid - yes & $612(64.2)$ \\
\hline Beta blockers - yes & $476(49.9)$ \\
\hline Clopidogrel - yes & $274(28.8)$ \\
\hline Statins - yes & $511(53.6)$ \\
\hline Hypoglycemic agents - yes & $279(29.3)$ \\
\hline Insuline - yes & $122(12.8)$ \\
\hline Anticoagulant - yes & $70(7.3)$ \\
\hline Angiotensin-converting enzyme inhibitor - yes & $456(47.8)$ \\
\hline Antithrombotic - yes & $17(1.8)$ \\
\hline Calcium blockers - yes & $162(17.0)$ \\
\hline
\end{tabular}

In addition, each of the 14 items loaded into the factor for which it was designed. None of the items loaded into more than one of the factors. The Cronbach's alpha for the combined items of the HADS 14 items was 0.88 , with a high reliability also obtained for the anxiety and depression factors (Table 2).

Adequate congruence coefficients were obtained for the anxiety factor $(0.95, p=0.001)$ and depression factor (0.91, $\mathrm{p}=0.001)$.

\section{Discussion}

Given the high prevalence and comorbidity of anxiety, depression, and $\mathrm{CVD}^{2}$ and the negative consequences in health and quality of life carried out by their simultaneous presentation ${ }^{8,9}$, there is a need for a valid, reliable,

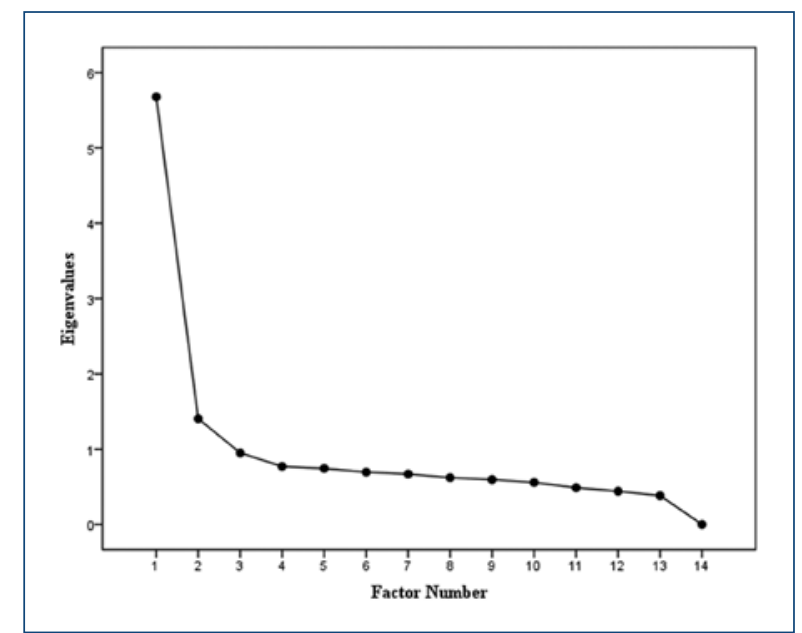

Figure 1. Scree plot of the HADS showing the 2-factor solution of the instrument.

and easy to apply measure to assess and then treat such emotional disorders in the setting of medical practice. The HADS was specially designed to fulfill this purpose ${ }^{14}$. Thus, the aim of the present study was to evaluate the basic psychometric properties of the HADS Spanish version in Mexican patients with a confirmed diagnosis of ischemic or hypertensive cardiomyopathy. According to our data, the Spanish version of HADS is characterized by construct validity and reliability in Mexican patients with CVD, what is reflected in its factorial structure and internal consistency coefficients, respectively.

First, in our sample, a bifactor structure integrating all items for anxiety and depression in two different scales allows the identification and differentiation of both emotional disorders as in the original version of the instrument and in contrast with the one single factor found by Herrera, Galindo, and Lerma ${ }^{22}$ in a smaller and less controlled (for cognitive deficit or psychiatry disorder presence) sample of Mexican patients with CVD.

This is important because, although anxiety and depression coexist in many patients, there are patients who only require treatment for one of such conditions, and at least psychological interventions for each emotional problem are quite different. Thus, a measure that identifies and differentiates the presence and severity of both conditions is much more clinically useful in terms of prescription of needed treatment in a more parsimonious way. For example, in the case of evidence-based behavioral intervention, patients with only anxiety will require relaxation training ${ }^{27}$ that is not 
Table 2. Exploratory factor analysis and internal consistency - HADS 14 items

Items

A13 I get sudden feelings of panic

A1 I feel tense or "wound up"

A5 Worrying thoughts go through my mind

A3 I get a sort of frightened feeling like something awful is about to happen

A11 I feel restless as if I have to be on the move

0.652

A9 I get a sort of frightened feeling like "butterflies in the stomach"

0.538

A7 I can sit at ease and feel relaxed

D14 I can enjoy a good book or radio or TV program

D2 I still enjoy the things I used to enjoy

$0.147 \quad 0.906$

D4 I can laugh and see the funny side of things

D12 I look forward with enjoyment to things

D10 I have lost interest in my appearance

HADS: Hospital anxiety and depression scale.

mandatory for those with only depression, which must need behavioral activation ${ }^{28}$ (that is not the main strategy to treat anxiety). The screening capacity of the instrument for depression and anxiety is a valuable tool for most of the public health institutions in Mexico, where human and material resources for mental health are limited.

In addition, according to Nunnally's suggestion for the interpretation of Cronbach's alpha coefficients (to consider them high as from 0.70$)^{24}$, the internal consistency indexes were adequate for both anxiety (0.82) and depression (0.83) scales. These findings are consistent with those obtained from the original version of the instrument $(0.83 \text { and } 0.80 \text {, respectively })^{1}$, in different countries, including Mexico, and diverse groups of patients ${ }^{2,15-20}$, showing a bi-factorial structure of the HADS. ${ }^{16-20}$. In addition, the high coefficients obtained in the congruence analysis give further support of the adequacy of the scale for its use in patients from medical settings.

\section{Conclusion}

The present study adds evidence of the validity and reliability of the HADS to assess the presence of both depression and anxiety in Mexican patients with chronic medical diseases, in general, and with CVD, in particular. Its central contribution, given the previous studies in Mexican HIV patients and CVD samples that showed unifactorial structures that suggest the measurement of distress in general, is that it demonstrates the capacity of the measure to also differentiate the presence and severity of the two emotional problems most frequently in medically ill population, depression, and anxiety. This makes the HADS an adequate tool to understand the specific experience of suffering in the setting of medical practice, and the explicit intervention needed to reduce it.

\section{Conflicts of interest}

The authors have no conflicts of interest. 


\section{Funding source}

None.

\section{Acknowledgments}

The authors thank the patients for their participation in the study. The authors also want to acknowledge: Úrsulo Juárez, Carlos Arellano, Manuel Odin de los Ríos, Mario Alberto Benavides, Eduardo Pérez, Manuel Barrera, Jorge Carillo, Natalia Peña, Marco Alcocer, Luz Rivera, José Luis Leiva, Ramón Arellano, José Antonio Magaña, Guillermo Duran, and Ana Gutiérrez as the physicians that made all the clinical evaluations.

\section{Ethical disclosures}

Protection of human and animal subjects. The authors declare that no experiments were performed on humans or animals for this study.

Confidentiality of data. The authors declare that they have followed the protocols of their work center on the publication of patient data.

Right to privacy and informed consent. The authors have obtained the written informed consent of the patients or subjects mentioned in the article. The corresponding author is in possession of this document.

\section{References}

1. Cohen J. The global burden of disease study: a useful projection of future global health? J Public Health Med. 2000;22:518-24.

2. Roberge $P$, Doré I, Menear M, et al. A psychometric evaluation of the french Canadian version of the hospital anxiety and depression scale in a large primary care population. J Affect Disord. 2013;147:171-9.

3. Moryś JM, Bellwon J, Adamczyk K, et al. Depression and anxiety in patients with coronary artery disease, measured by means of selfment Kardiol Pol. 2016;74:53-60.

4. Morris AA, Zhao L, Ahmed Y, et al. Association between depression and inflammation-differences by race and sex: the META-health study. Psychosom Med. 2011;73:462-8

5. Anda R, Williamson D, Jones D, et al. Depressed affect, hopelessness, and the risk of ischemic heart disease in a cohort of U.S. Adults. Epidemiology. 1993:4:285-94.

6. Musselman DL, Evans DL, Nemeroff CB. The relationship of depression to cardiovascular disease: epidemiology, biology, and treatment. Arch Gen Psychiatry. 1998;55:580-92.
7. Barth J, Schumacher M, Herrmann-Lingen C. Depression as a risk factor for mortality in patients with coronary heart disease: a meta-analysis. Psychosom Med. 2004;66:802-13.

8. Malzberg B. Mortality among patients with involution melancholia. Am J Psychiatry. 1937;93:1231-8.

9. Baune BT, Stuart M, Gilmour A, et al. Moderators of the relationship between depression and cardiovascular disorders: a systematic review. Gen Hosp Psychiatry. 2012;34:478-92.

10. Glassy CM, Lemus H, Cronan T, Glassy MS, Talavera GA. Relationship between depressive symptoms and cardiovascular risk factors among selected latino patients at a community clinic. Psychol Health Med. 2010;15:117-26.

11. Krishnan KR. Depression as a contributing factor in cerebrovascular disease. Am Heart J. 2000;140:70-6.

12. Lichtman JH, Bigger JT Jr., Blumenthal JA, et al. Depression and coronary heart disease: recommendations for screening, referral, and treatment: a science advisory from the American heart association prevention committee of the council on cardiovascular nursing, council on clinical cardiology, council on epidemiology and prevention, and interdisciplinary council on quality of care and outcomes research: endorsed by the American psychiatric association. Circulation. 2008:118:1768-75.

13. Bunevicius A, Staniute M, Brozaitiene J, et al. Screening for anxiety disorders in patients with coronary artery disease. Health Qual Life Outcomes. 2013;11:37.

14. Zigmond AS, Snaith RP. The hospital anxiety and depression scale. Acta Psychiatr Scand. 1983;67:361-70.

15. Bjelland I, Dahl AA, Haug TT, Neckelmann D. The validity of the hospital anxiety and depression scale. An updated literature review. J Psychosom Res. 2002:52:69-77.

16. Haddad $M$, Walters $P$, Phillips $R$, et al. Detecting depression in patients with coronary heart disease: a diagnostic evaluation of the PHQ-9 and HADS-D in primary care, findings from the UPBEAT-UK study. PLOS One. 2013;8:e78493

17. Meléndez JA, Bustinzar AR, de la Vega Morales RI, Chávez-Peón PB, Moreno LR. Validation of the hospital anxiety and depression scale in Mexican population with eating disorders. Rev Mex Trastor Aliment. 2017;8:123-30.

18. Vázquez OG, Benjet $\mathrm{C}$, García FJ, et al. Propiedades psicométricas de la escala hospitalaria de ansiedad y depresión (HADS) en una población de pacientes oncológicos Mexicanos. Salud Ment. 2015;38:253-8.

19. Orozco MJ, Terán BP, Casarrubias VB, et al. Escala de ansiedad y depresión hospitalaria (HADS): validación en pacientes mexicanos con infección por VIH. Psicol Iberoam. 2013;21:29-37.

20. López-Alvarenga JC, Vázquez-Velázquez V, Arcila-Martínez D, et al. Exactitud y utilidad diagnóstica del hospital anxiety and depression scale $(\mathrm{HAD})$ en una muestra de sujetos obesos mexicanos. Rev Invest Clin. 2002;54:403-9.

21. Vázquez ÓG, Meneses AG, Herrera ÁG, et al. Escala hospitalaria de ansiedad y depresion (HADS) en cuidadores primarios informales de pacientes con cáncer propiedades psicométricas. Psicooncologia. 2015;12:129-40.

22. Navarrete BH, Galindo OV, Talamantes AL. Inventario de ansiedad y depresión hospitalaria y escala de retiro de patrón de conducta tipo a en pacientes con enfermedades cardiovasculares: propiedades psicométricas. Psicol Salud. 2018;28:121-30.

23. Ebel R, Frisbie D. Essentials of Educational Measurement. $4^{\text {th }}$ ed. Englewood Cliffs, New Jersey: Prentice Hall; 1988.

24. Nunnally JC. Educational Measurement and Evaluation. $2^{\text {nd }}$ ed. New York: McGraw-Hill; 1987.

25. Cueto EG. Coeficiente de congruencia. Psicotherma. 1994:6:465-8.

26. Lara SA. Coeficiente de congruencia : propuesta de cálculo. Pensando Psicol. 2013;9:107-9.

27. Manzoni GM, Pagnini F, Castelnuovo G, Molinari E. Relaxation training for anxiety: a ten-years systematic review with meta-analysis. BMC Psychiatry. 2008;8:41

28. Mazzucchelli T, Kane R, Rees CS. Behavioral activation treatments for depression in adults: a meta-analysis and review. Clin Psychol Sci Pract. 2009;16:383-411. 